\title{
ASSESSMENT OF IONIZED CALCIUM STATUS IN FEBRILE SEIZURES
}

\author{
Sandeep Kumar Sharma ${ }^{1}$, Niranjan Singh ${ }^{2}$, K.V.Thimmaraju ${ }^{3}$, Mona Tilak ${ }^{4}$. \\ ${ }^{1}$ Associate professor, ${ }^{2}$ Assistant Professor, ${ }^{3}$ Professor, Department Of Biochemistry, Varun Arjun Medical College, \\ Shahjahanpur, U.P., India. ${ }^{4}$ Professor, Department of Biochemistry, \\ Dr. D. Y. Patil Medical College Pune, Maharashtra, India.
}

\section{ABSTRACT}

Introduction: Epilepsy is one of the most common disorders of the brain. One of every ten people will have at least one epileptic seizure during a normal lifespan, and a third of these will develop epilepsy. In children the most common forms of convulsion are febrile seizures. Water electrolyte imbalance occurs during acute febrile illness and hypocalcaemia is one of them. Hypocalcaemia is also present in cases of seizures. To find out significance of calcium levels in cases of seizures this study was conducted. Aims: To assess the level of ionized calcium in cases of febrile seizure. Methods: This Case - Control study was conducted on fifty cases of febrile seizures and fifty age, weight matched controls and calcium deficiency determined in both groups. The serum ionized calcium levels were estimated by ion selective electrode method using $\mathrm{Na}, \mathrm{K}, \mathrm{Ca}$ analyzer. Results: Mean ionized calcium level was $4.62 \pm 0.26 \mathrm{mg} /$ $\mathrm{dl}$ and $4.88 \pm 0.27 \mathrm{mg} / \mathrm{dl}$ in study and control groups respectively and this difference was found statistically extremely significant $(p<0.001)$. Conclusion: The findings suggest that a considerable percentage of children having febrile seizures are suffering from low level of calcium.

KEYWORDS: Hypocalcemia; Serum calcium; Febrile seizures.

\section{INTRODUCTION}

Epilepsy is one of the most common disorders of the brain[1]. In normal lifespan at least one person in every ten is having epileptic seizure, out of which third will develop epilepsy. Approximately 50 million people are suffering from epilepsy worldwide. According to a World Health Organization (WHO), epilepsy shares 1\% of the global burden of disease, which is equivalent to breast cancer in women and lung cancer in men [2].

The terms convulsive disorder, seizure disorder and cerebral seizures are used synonymously with epilepsy. They all refer to recurrent paroxysmal episodes of brain dysfunction manifested by stereotyped alterations in behavior [1].

A sudden change in the behavioral activity or dynamic with in limited time is called convulsion and results from the abnormal electrical activity of the brain [3]. Children are more susceptible to develop convulsion and one of the most common forms of convulsion in

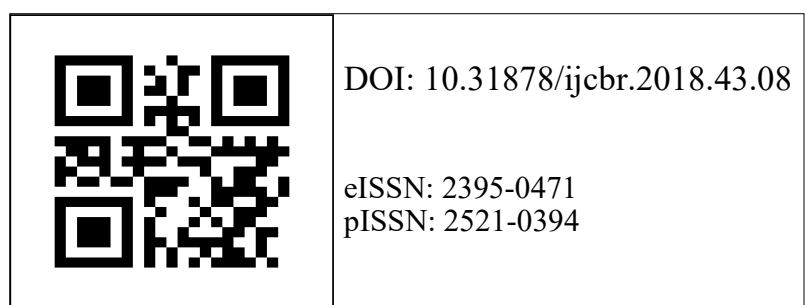

children are febrile seizures which occur in $2-5 \%$ of children aged between 6 months and 5 years [4,5]. According to American Academy of Pediatrics (AAP), febrile seizures occur in the absence of central nervous system infection, metabolic disorders and in absence of a history of prior afebrile seizures [6]. Usually good prognosis is seen in febrile seizure; however, but increase in it's recurrence increases the risk of epilepsy in the future, they are considered as serious conditions [7]. Etiology of febrile seizures is yet to be determined precisely. Some of the conditions involved in the etiology of febrile seizures include the family history of febrile seizures and alcohol and cigarette consumption by the mother during pregnancy [8,9]. Prematurity, complications during childbirth and recent vaccination are among other risk factors of febrile seizures [10]. Inadequately evolved electrical system of the brain is responsible for febrile seizure as it is unable to struggle against the stress of rise in body temperature [11].

A common biochemical abnormality causing seizures is hypocalcaemia, which may manifest as muscle cramps, tetany, seizures and paraesthesia [12]. During any acute febrile disease, disturbances in water and electrolytes occur frequently. It has been suggested that change in serum calcium might enhance the susceptibility to seizures.

Correspondence: Dr. Niranjan Singh, Assistant Professor, Department of Biochemistry, Varun Arjun Medical College, Shahjahanpur, U.P. India. E-mail: niranjandugtal@gmail.com 


\section{MATERIALS AND METHODS}

Study design: Case control prospective analytical study

Study location: This hospital based case control study was conducted at the Department of Biochemistry, Varun Arjun Medical College, Shahjahanpur, U.P.

\section{Study period: 15 October 2017 to 31 May 2018}

Sample size and method: In the present study total 100 participants were included based on inclusion and exclusion criteria.

Sample selection: India on 100 subjects out of which 50 were cases of febrile convulsion between the ages of 6 months to 5 years. 50 members' age and weight matched children suffering from a febrile illness without seizures, such as urinary tract infection, gastroenteritis and respiratory tract infection served as controls.

Inclusion Criteria: Children with simple/complex febrile seizures (seizure occurring in developmentally normal child in association with a febrile illness in the absence of CNS infection or any other defined cause of seizures).

Exclusion Criteria: Children with previous history of established non febrile seizures, neurological infections (meningitis, encephalitis), hereditary metabolic disorders, developmental delay, children with history of birth asphyxia and persistent neurological deficits

Data Collection: Demographic data, seizure details, nature of febrile illness, complete developmental history, family history of epilepsy/febrile seizures, temperature at admission, general examination, Systemic examination and nutritional status were recorded (IAP weight for age classification was used to grade protein energy malnutrition) including the final diagnosis was recorded.

Grouping: Study group: 50 were cases of febrile convulsions.

Control group: 50 patients suffering from a febrile illness without seizures

Methodology: Demographic data, seizure details, nature of febrile illness, complete developmental history, and family history of epilepsy /febrile seizures was recorded. The serum ionized calcium levels were estimated by ion selective electrode method using $\mathrm{Na}, \mathrm{K}, \mathrm{Ca}$ analyzer.

Statistical analysis: Data was collected from eligible patients on a pre-structured pre-tested Proforma. For data analysis statistical software SPSS-20 version was used and data were analyzed with the help of proportions, measures of central tendency and appropriate statistical test.

\section{RESULTS}

Mean age was $2.16 \pm 1.08$ years and $2.12 \pm 0.82$ years in study and control group respectively and this difference was found statistically insignificant ( $p>0.05)$.

In present study, male predominance over females in both study and control groups, where total $70 \%$ and $64 \%$ patients were males in study and control groups respectively. On applying chi square test, the gender difference was found statistically insignificant ( $p>0.05$ ).

Table 1. Distribution of cases according to lonized Calcium $(\mathrm{mg} / \mathrm{dl})$ level in both groups

\begin{tabular}{|l|l|l|}
\hline \multirow{2}{*}{$\begin{array}{l}\text { Ionized Calcium } \\
(\mathrm{mg} / \mathrm{dl})\end{array}$} & \multicolumn{2}{|l|}{ Grouping } \\
\cline { 2 - 3 } & $\begin{array}{l}\text { Control } \\
\mathrm{N}(\%)\end{array}$ & $\begin{array}{l}\text { Test } \\
\mathrm{N}(\%)\end{array}$ \\
\hline Abnormal (<4.4) & 0 & $12(24)$ \\
\hline Normal (4.4-5.54) & $50(100)$ & $38(76)$ \\
\hline Ionized Calcium & $4.88 \pm 0.27$ & $4.62 \pm 0.26$ \\
\hline $\mathrm{T}$ & 4.871 & \\
\hline P value & $<0.001$ & \\
\hline
\end{tabular}

According to above table, in study group, 12 (24\%) patients had abnormal $(<4.4 \mathrm{mg} / \mathrm{dl})$ range of ionized calcium level while in control group no patient had abnormal ionized calcium level.

Mean ionized calcium level was $4.62 \pm 0.26 \mathrm{mg} / \mathrm{dl}$ and $4.88 \pm 0.27 \mathrm{mg} / \mathrm{dl}$ in study and control groups respectively and this difference was found statistically highly significant $(p<0.001)$.

\section{DISCUSSION}

Convulsions or seizures are one of the important pediatric health problems in developing and developed countries and febrile seizures are the most common seizure disorder in childhood, affecting $2 \%$ to $5 \%$ of children between the ages of 6 and 60 months 1 . It is generally believed that FS is an age-dependent response of the immature brain to fever. This postulation is supported by the fact that most $(80-85 \%)$ febrile seizures occur between 6 months and 3 years of age, with the peak incidence at 18 months. Studies based on animal models suggest that there is enhanced neuronal excitability during the normal brain maturation but the exact mechanism is still unclear [2].

In our study Mean ionized calcium level was $4.62 \pm 0.26 \mathrm{mg} / \mathrm{dl}$ and $4.88 \pm 0.27 \mathrm{mg} / \mathrm{dl}$ in study and control groups respectively and this difference was found statistically highly significant $(p<0.001)$.

In a study by Akbayramset al [13] where 48 children with febrile seizures were compared with age matched 
controls and found low serum calcium $(P=0.001)$. In literature there are inadequate studies relating serum calcium in children with febrile seizures.

Our observation is also similar to studies by Chiarelli $\mathrm{F}$ et al. where Serum levels of sodium and calcium were significantly lower in children with FS. [14] There was no association between low Serum calcium and FS in studies by N. Rutter et al and Sayedzadeh S A et al.[15,16]

\section{CONCLUSION}

The findings suggest that a considerable percentage of children having febrile seizures are suffer from calcium deficiency and gender have insignificant role.

Limitation: Further required in large population to conform the result.

\section{REFERENCES}

1. World Health Organization. Atlas: Epilepsy Care in the World. Geneva: World Health Organization; 2005. [cited 2018 June. 20].Available from: http:// www.who.int/whr/2005/en/whr01_en.pdf

2. Johnston MV. Seizure in childhood: febrile seizure. 17th ed. In: Nelson's text book of pediatrics, Behrman RE, Kliegman RM, Jenson HB, eds. Pennsylvania: Saunders; 2004. pp. 1994-5.

3. Fallah R, Golestan M. Role of laboratory diagnostic tests in first febrile seizure. J Pediatr Neurol. 2008; 6(2): 129- 132.

4. Miri-Aliabad G, Khajeh A, Fayyazi A and Safdari L. Clinical, epidemiological and laboratory characteristics of the patients with febrile convulsion. J ComprPediatr. 2013; 4(3): 134-7.

5. Graves RC, Oehler K, Tingle LE. Febrile seizures: Risks evaluation and prognosis. Am Fam Physician. 2012; 85(2): 149-53.

6. Kafadar I, Akıncı AB, Pekün F and Adal E. The role of serum zinc level in febrile convulsion etiology. J Pediatr Inf. 2012; 6: 90-93.

7. Salehiomran MR, Mahzari M. Zinc status in febrile seizure: A case-control study. Iran J Child Neurol. 2013; 7(4): 20-23.

8. Miri-Aliabad G, Khajeh A, Arefi M. Iron status and iron deficiency anemia in patients with febrile seizure. Zahedan J Res Med Sci. 2013; 15(9): 14-17.

9. Mahyar A, Ayazi P, Fallahi M and Javadi A. Risk factors of the first febrile seizures in Iranian children. Int J Pediatr. 2010;1-3.
10. Vestergaard M, Hviid A, Madsen KM, et al. MMR vaccination and febrile seizures: Evaluation of susceptible subgroups and long-term prognosis. JAMA. 2004; 292(3): 351-357.

11. Burhanoğlu $M$, Tütüncüoğlu $S$, Coker $C$, et al. Hypozincaemia in febrile convulsion. Eur J Pediatr. 1996; 155(6): 498-501.

12. Malhotra Y, Campbell D. Pediatric hypocalcemia, 2014. Available at: http:// www.emedicine.medscape.com/ article/9218440verview/ Presentation/DDx/ Workup/Treatment/Me dication. Accessed july 2017.

13. Akbayram S, Cemek M, Buyukben A, Aymelek F, Karaman $S$ et al. Major and minor bio-element status in children with febrile seizure. BratislLekListy 2012; 113(7):421-3.

14. Chiarelli F, De Palma C, Verrotti A, Lombardi G, Domizio S: Electrolytic changes in febrile convulsions. Pediatr Med Chir. 1985;7(2):249-52.

15. Rutter N. and Smales ORC. Calcium, magnesium, and glucose levels in blood of children with febrile convulsions. Archives Dis Childhood. 1976;51:141.

16. Sayedzadeh SA, Hemati M. Serums Sodium and Calcium Level in Children with Simple and Recurrent Febrile Convulsion. J Comprehens Pediatr. 2013;3(5):179-83.

How to Cite this article: Sandeep Kumar Sharma, Niranjan Singh, K.V.Thimmaraju, Mona Tilak. Assessment of ionized calcium status in febrile seizures. Int. j. clin. biomed. res. 2018;4(3): 35-37. 